\title{
Phantasy and Vocational Choice
}

\author{
WM. CLARK TROW
}

University of Michigan

\begin{abstract}
$\star$ Believing that questions on vocational interest blanks may tempt pupils to wishful thinking or phantasy in listing their occupational choices, the autbor prepared an interest blank for a sampling of Detroit high school pupils. The findings and an interpretation of the results are given in this article.
\end{abstract}

$\mathrm{Q}$ UestionNarre studies of vocational interests usually conclude that young people's aspirations far exceed their abilities and opportunities, and, as a consequence, job dissatisfaction is common. For example, in the New York State Regents Inquiry we find such statements as the following:

The inclination of all was to choose on professional levels in numbers out of proportion to opportunity. Many from economically poor homes planned on careers out of the question financially. Many with poor records had in mind careers reached only through graduate schools. ${ }^{1}$

Similarly, in the Maryland Survey, ${ }^{2}$ a table is entitled: "The Jobs Youth Want and the Jobs They Get." And one conclusion reads:

More than five times as large a proportion of the employed subjects expressed a desire to do professional-technical work as were found to be employed in this field.

${ }^{1}$ F. T. Spaulding, High Scbool and Life-Report of Regents Inquiry. New York, McGraw-Hill, 1938, resumé from pp. 56-57.

${ }^{2}$ Howard M. Bell, Youtb Tell Their Story. Pp. 131-34. American Council on Education, Washington, 1938.
The same evidence comes from those who use the Strong Vocational Interest Blank.

If on the basis of interest-questionnaire returns, our youth seem to be lacking in realism; if there is a discrepancy between abilities and opportunities, on the one hand and stated vocational interests, on the other, at least two explanations may be offered. One admits that the condition exists, but places the blame on inadequate vocational counseling. The other denies or minimizes the condition, which is viewed as the spurious result of faulty research technique. It is probable that both explanations have a basis in fact. And certainly a measure of plausibility is furnished the latter contention when some of the directions and questions commonly used on vocational interest blanks are carefully reviewed. They are uniformly high in suggestion value. They clearly waive all practical considerations and ask what the questionee "would like." He follows the directions on the blank and realizes his daydream, imaginatively, for a moment or two. The error comes in interpreting the item checked as a vocational choice.

\section{High Suggestion Valub}

The following are samples of some of the questions taken from personnel blanks, which seem to have a high suggestion value, in that the wording of the question compels the pupil to answer on the basis of wishful thinking and phantasy:

From the Maryland Survey: "Regardless of available opportunities, what kind of work would you most like to do?"

From the Strong Vocational Interest Blank: "Indicate after each occupation 
listed below whether you would like that kind of work or not. ... Y You are not asked if you would take up the occupation permanently, but merely whether or not you would enjoy that kind of work, regardless of any necessary skills, abilities, or training which you may or may not possess."

From others: "You are not asked whether you would take up the occupation permanently, but merely whether you would enjoy that kind of work."

"If you had your choice, what would be your present occupation?"

"If you had your choice, what would be your occupation ten years from now?"

"If you were financially able, and free to choose witbout restriction, what kind of work would you like to prepare for?"

"If you could do exactly as you wish, what would you be doing 10 or 15 years from now?"

"If you could do anytbing you wanted to, 3 what job would you choose?"

Are the vocational choices of young people as unrealistic as one might think? Are disappointment and job dissatisfaction to be expected?

The replies of a sampling of 330 pupils, 161 boys and 169 girls, in the eighth, tenth, and twelfth grades in three Detroit schools to three questions of an interest blank devised by the writer were studied

${ }^{3}$ Iralics in these quotarions are the writer's. intensively. ${ }^{4}$ The three questions were worded to discriminate three stages which may be distinguished as probability, possibility, and phantasy. They were stated as follows:

Question I, Probability: "What kind of job do you think you will probably be able to do when you are throughschool?"

Question 2, Possibility: "If you could be sure to get the education and training that you would need, what kind of job would you choose?"

Question 3, Phantasy: "People sometimes think about what they would like to be although they don't really believe it could ever come true. If by some magic you could be anything you want, what would you like to be?"

If the job these high school pupils think they will be able to do (Question I) is the "same" as the one they would choose (Question 2), they may be said to be satisfied with the outlook. This was true of 40 per cent of the cases (see Table I). The 39 per cent who gave "different" answers for Questions I and 2 might expect some job dissatisfactions if they definitely dislike their probable occupation, which, however, does not seem to be the case. Other similarities and discrepancies are shown in TABLE I. Little differentiation was found for sex, grade, or intelligence

4 R. J. Gatien and Gerald Poor actively participated in gathering and summarizing the data here reported.

\section{TABLE I}

Relative Number of Pupils Who Made the Same and Different Choices for The Three Questions

\begin{tabular}{|c|c|c|c|c|c|c|c|c|}
\hline \multirow[b]{3}{*}{ Questions } & \multicolumn{4}{|c|}{ Same } & \multicolumn{4}{|c|}{ Different } \\
\hline & \multirow{2}{*}{$\begin{array}{l}\text { No. } \\
\text { Tot. }\end{array}$} & \multicolumn{3}{|c|}{ Per Cent } & \multirow{2}{*}{$\begin{array}{l}\text { No. } \\
\text { Tot. }\end{array}$} & \multicolumn{3}{|c|}{ Per Cent } \\
\hline & & Tot. & Job & Inc.* & & Tot. & Job & Inc.* \\
\hline$I, 2$ & I5S & 47 & 40 & 7 & I75 & 53 & 39 & I4 \\
\hline $1,2,3$ & 55 & 17 & 12 & 5 & 275 & 83 & 59 & 24 \\
\hline 2,3 & 106 & 32 & 25 & 7 & 224 & 68 & 52 & 16 \\
\hline
\end{tabular}

* "Inc." signifies incomplete replies, one or more questions being left blank or answered, "I don't know." Two blanks or "I don't knows" were tabulated "same" for any two questions; one of each, "different." 
TAble II

Average Liking Scores on Questions i and 2 for Those Who Gave the Same aNd Different ANswers

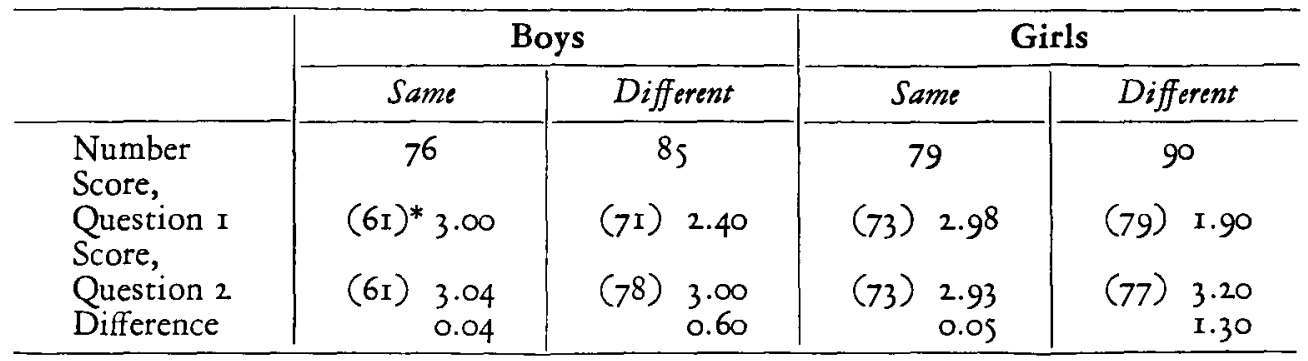

* Figures in parentheses indicate the number of pupils in each case who rated their degree of liking.

level from the replies to these two questions.

Further significance is found in the ratings made by the pupils of their degree of liking for the occupations of their choice. The ratings were made for Questions I and 2 on an eight-point graphic scale. The zero-point in the center signified indifference. Be it said for youthful expectations, the left or disliking end of the scale was little used. The directions for the positive end read: " 2 means you like it; 4 means you like it more than anything else."

The average liking scores of both boys and girls who wrote down the "same" occupational choice for Questions I and 2 were all close to 3 on the scale ( $T_{A B L E}$ II), signifying a high degree of satisfaction. The differences of 0.04 and 0.05 are only chance differences. The average liking scores when the probable occupation (Question I) was "different" from the one they would like (Question 2) show a greater discrepancy, the difference for the girls being much greater (1.30); but that for the boys (0.6) has a reliability of 3.I. Thus the pupils distinguished the implications of the two questions, and they were fairly well satisfied with either possibility.

\section{Comparison with Census Data}

The categories of the choices made by these high school pupils were next ex- plored to compare them with the percentage of employed persons in these categories. The percentage of persons employed in the ten Census classifications was available for the country as a whole, for the state of Michigan, and for the city of Detroit. The percentage of pupils reporting choices in these same classifications in response to Questions I, 2, and 3 was computed and is compared with the Census data, in TABLE III. (A second administration of the interest questionnaire to a group of $4 \mathrm{r}$ high school pupils after an interval of five months gave a contingency correlation for Question I based on occupational classifications of 0.935 , indicating a high degree of reliability.)

TABLE III affords an opportunity for a number of interesting observations, but most significant for the present purpose are the choices in Group D which show the usual discrepancy between unskilled occupations and vocational choice, Group $\mathrm{H}$ which presents the converse of Group $D$, and Group J. In this latter group, where the overemphasis on clerical occupations was chiefly from the girls, the declining number of responses in Questions 2 and 3 indicates a lack of enthusiasm for this occupational outlet.

The high per cent of choices in the professional group (Group $\mathrm{H}$ ) seems at first glance to be in accord with the other studies-the same high hopes, to be fol- 
lowed by disappointment and job dissatisfaction. For example, the per cents in the Professional category in the Maryland Survey were 43. I for the total group and 38.3 for the employed youth, as compared with $32.7,50.9$, and 42.4 for Questions I, 2, and 3 , respectively.

\section{INTERPRETING THE DATA}

These data, however, will bear closer scrutiny. For the "probable" occupation (Question I), the Detroit young people chose occupations in the professional category in a notably smaller per cent of the cases than even the Maryland youth, in spite of the fact that they were a much more highly selected group, as will be shown later. For the "possible" occupation (Question 2), the large number of interests in the professional category ( 50.9 per cent) is a direct consequence of the explicit suggestion in the question: "If you could be sure to get the education and training that you need. ..."

It will be recalled that the question in the Maryland Survey was as follows: "Regardless of available opportunities, what kind of work would you like most to do? (Italics mine.) It is probable that this question elicited much the same kind of "phantasy" replies as Question 3. Certainly, the 43.I per cent and 42.4 per cent of the two studies are closely comparable. It is probable that a different wording in the Maryland Survey would have brought a reduced number into this classification just as Question I did for the Detroit sample.

However, the two groups were widely different. The Maryland Survey was made on what was very nearly a random sampling of the total youth population; whereas the school children in Detroit, on the basis of intelligence, represent a decidedly skewed distribution with a larger number of pupils at the upper than at the lower end. Intelligence test scores are obtained on all children in the Detroit schools. The pupils chosen represent a fair sampling of the schools from which they come, but these schools are much above the average of the schools for the city as a whole with respect to intelligence rating. Forty-one per cent of the boys and 25 per cent of the girls from X H. S. go on to college, and about half of this number graduate. For the sample studied, the intelligence of 39.7 per cent was in the A and B categories (I. Q. I Io or higher) instead of a probable 20 per cent in a random sampling. Hence, the 32.7 per cent who picked their probable occupation in the Professional Service category (Question I) may be making realistic choices after all; and even a goodly number out of the 42.4 per cent

TABLE III

Comparison in Per Cent of Occupational Choices with i93o Census Crassification

\begin{tabular}{|c|c|c|c|c|c|c|c|}
\hline Group & Classification & U. S. & Mich. & Detroit & I & 2 & $3^{*}$ \\
\hline A & Agriculture & $25 . I$ & $15 \cdot 4$ & 0.3 & 0 & 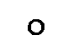 & 0.3 \\
\hline B & Forestry, Fishing & 0.7 & 0.8 & o & o & 0.3 & o \\
\hline $\mathrm{C}$ & Extraction of Minerals & 2.6 & I. 3 & 0.1 & $\circ$ & 0 & o \\
\hline$\vec{D}$ & Manufacg. Mechan. Indus. & 32.1 & 46.6 & $4^{8} \cdot 5$ & 5.2 & 3.0 & .6 \\
\hline $\mathrm{E}$ & Transportn., Communicn. & 9.4 & $7 \cdot 9$ & 6.9 & 2.7 & 5.4 & 6.0 \\
\hline $\mathrm{F}$ & Trade & $13 \cdot 4$ & 12.5 & 13.9 & I2. 1 & 7.0 & 5.8 \\
\hline G & Public Service & 2.2 & 2.2 & 2.4 & I. 8 & 2.7 & $3 \cdot 3$ \\
\hline $\mathrm{H}$ & Professional Service & $4 \cdot 5$ & 4.2 & 6.2 & 32.7 & 50.9 & 42.4 \\
\hline I & Domestic, Persl. Service & $4 \cdot 7$ & 4.0 & 10.4 & $\cdot 9$ & 2. I & I. 5 \\
\hline $\mathrm{J}$ & Clerical & $5 \cdot 4$ & S.I & II. 3 & 27.0 & $14 \cdot 5$ & $3 \cdot 3$ \\
\hline
\end{tabular}

* In the last three columns, per cents of the total group of 330 pupils are given. A number of pupils, particularly in reply to Question 3, either did not reply or wrote "I don't know," hence these columns do not total 100 per cent. 
whose phantasy choices were in this category (Question 3) have a fair chance of having their dream come true. It is even possible that a substantial proportion of the 50.9 per cent who chose in this category in response to Question 2 may be rewarded at least by having a job in this occupational classification, if not the one of their choice. The Census Professional Service classification includes not only civil engineers, physicians, lawyers, and teachers, but also billiard room, dance hall, and skating rink keepers, theater ushers, and circus helpers!

\section{Conclusions}

In general it may be concluded, for the sample of high school children studied, that (I) they are realistic in that they can distinguish between "probability," "possibility," and "phantasy" choices; (2) as a rule they are satisfied with their voca- tional outlook since there is no discrepancy, for about half of them, between what they will probably do and what they would like to do, and since on the average they express more than a moderate degree of liking for either possibility; and (3) their proportion of plans and expectations is in general harmony with occupational possibilities for this high intelligence sampling.

There is no indication, however, that more effective vocational guidance might not be desirable. In general, it may be said that it seems quite legitimate to ask young people what they would like to do or be, apart from all considerations of training and opportunity, as is done on most vocational interest questionnaires. But their replies should be interpreted as an indication of the direction of their interest, and not as a statement of their vocational expectations.

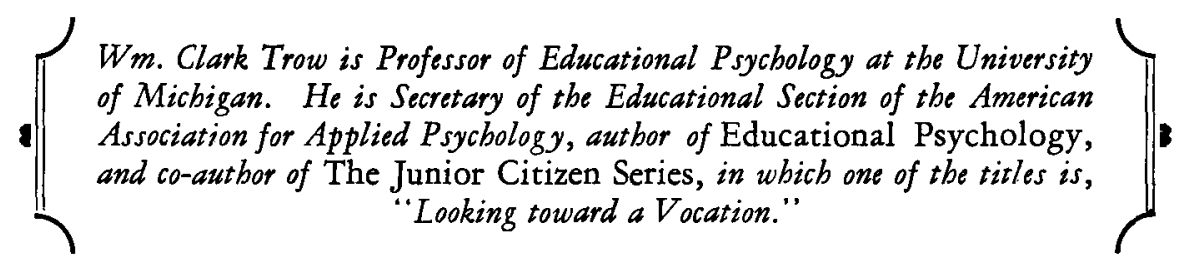

